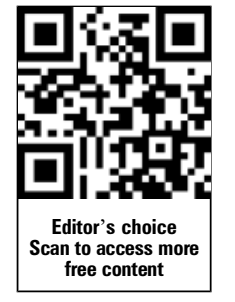

For numbered affiliations see end of article.

\section{Correspondence to} Professor Wayne Derman, UCT/MRC Research Unit for Exercise Science and Sports Medicine, Department of Human Biology, Faculty of Health Sciences, 3rd Floor Sports Science Institute of South Africa Boundary Road Newlands, Cape Town 7700 South Africa;

ewderman@iafrica.com

Accepted 25 February 2013

To cite: Derman $W_{1}$ Schwellnus $\mathrm{M}$, Jordaan $\mathrm{E}_{\mathrm{i}}$ et al. Br I Sports Med 2013;47:420-425

\title{
Illness and injury in athletes during the competition period at the London 2012 Paralympic Games: development and implementation of a web-based surveillance system (WEB-IISS) for team medical staff
}

Wayne Derman, ${ }^{1,2}$ Martin Schwellnus, ${ }^{1,2}$ Esme Jordaan, ${ }^{3}$ Cheri A Blauwet, ${ }^{4,5}$ Carolyn Emery, ${ }^{6,7}$ Pia Pit-Grosheide, ${ }^{5}$ Norma-Angelica Patino Marques, ${ }^{5,8}$ Oriol Martinez-Ferrer, ${ }^{5,9}$ Jaap Stomphorst, ${ }^{5,10}$ Peter Van de Vliet, ${ }^{5,11}$ Nick Webborn, ${ }^{12}$ Stuart E Willick ${ }^{5,13}$

\section{ABSTRACT \\ Background In this study we describe (1) the implementation of a novel web-based injury and illness surveillance system (WEB-IISS) for use by a team of physicians at multisport events and (2) the incidence and characteristics of injuries and illness in athletes during the London 2012 Paralympic Games.}

Methods Overall, 3565 athletes from 160 of the 164 participating countries were followed daily over a 14-day period, consisting of a precompetition period (3 days), and a competition period (11 days) (49 910 athletedays). Daily injury and illness data were obtained from teams with their own medical support (78 teams, 3329 athletes) via the WEB-IISS, and without their own medical support through the London Organising Committee of the Olympic Games and Paralympic Games database (82 teams and 236 athletes).

Results There were no differences between incidence rates (IR) of injury and illness, or between the precompetition and competition periods. The IR of injury during the competition period was 12.1/1000 athlete-days, with an incidence proportion (IP) of $11.6 \%$ (95\% Cl $11.0 \%$ to $13.3 \%$ ). Upper limb injuries (35\%), particularly of the shoulder (17\%) were most common. The IR of illness during the competition period was $12.8 / 1000$ athlete-days ( $95 \% \mathrm{Cl} 12.18$ to 1421$)$, with an IP of $10.2 \%$. The IP was highest in the respiratory system (27.4\%), skin (18.3\%) and the gastrointestinal (14.5\%) systems.

Conclusions During the competition period, the IR and IP of illness and injury at the Games were similar and comparable to the observed rates in other elite competitions. In Paralympic athletes, the IP of upper limb injuries is higher than that of lower limb injuries and non-respiratory illnesses are more common.

\section{INTRODUCTION}

Participation in elite sporting competition for athletes with a disability has seen significant growth in recent years. Indeed, involvement by athletes in the London 2012 Paralympic Games included a record number of participants with respect to both countries and athletes. There are relatively a few epidemiological studies relating to the monitoring of injury and illness in this population of athletes. Thus, detailed understanding of patterns of illness and injury in this complex area of sport and exercise medicine remains poorly understood. ${ }^{1-3}$

Injury and illness surveillance plays an integral role in the prevention of injury and the protection of athletes' health. ${ }^{4} 5$ In addition, it provides important information regarding the number, characteristics and aetiology of injury and illness and also provides an opportunity for monitoring longterm changes in their occurrence, thus allowing for the planning of interventions. ${ }^{67}$

While the incidence and characteristics of injuries during able-bodied international sporting tournaments including the Summer ${ }^{8}$ and Winter ${ }^{9}{ }^{10}$ Olympic Games, swimming, ${ }^{11}$ Track and Field World Championships' 13 and football ${ }^{514} 15$ and Rugby Union events, ${ }^{16}{ }^{17}$ have been well documented. There are a few epidemiological studies documenting injury at the Paralympic Games. ${ }^{1}{ }^{2}$ Webborn et al, ${ }^{1}{ }^{2}$ undertook injury surveillance studies at three consecutive editions of the Paralympic Winter Games and reported the incidence proportions (IP; percentage of athletes with injury) to be between $9 \%$ and $24 \%$ across all the winter sporting disciplines. Data from the Paralympic Summer Games have been mostly reported by team medical staff and have comprised the review of injuries from single countries. The IPs in these reports ranged from $56 \%$ to $110 \%$, indicating that a number of athletes experienced multiple injuries. ${ }^{18-20}$

In comparison to injury, illness in able-bodied athletes during major competition has been less commonly studied. IPs of illnesses range from 6.7 to $75 \%$ in single and multisport settings. ${ }^{11} 121416$ 172122 Illness epidemiology during the Paralympic Games has never been studied.

Yet, research to date has been fraught with significant limitations including a lack of consensus regarding the definition of reportable injury, unconfirmed medical diagnoses, lack of exposure data and small sample size. In particular the use of IP does not allow for comparison of injury and illness rates in competitions of different durations, and the use of incidence rates (IR; injuries/illnesses per exposure, eg, 1000 athlete-days) would be a preferable methodology.

In an attempt to address the lack of data in Paralympic athletes and to address some of the 
limitations of the research methodologies listed above, we developed and implemented a novel web-based injury and illness surveillance system (WEB-IISS) for use by team medical staff during major multisport events. Previous systems in use for major competitions have been mostly paper-based, or have relied on records sent via email. Utilising the setting of the London 2012 Paralympic Games with Wi-Fi available at all venues, allowed for the development and implementation of an online, web-based system which enabled the collection of more detailed data than has previously been described. Additionally, the use of this system enhanced compliance by team medical staff and facilitated the collection of exposure data, thus allowing for more accurate calculation of rates of illness and injury.

Therefore, by utilising a novel system (WEB-IISS), the aim of the present study is to report and compare the incidence and basic characteristics of injuries and illnesses in athletes participating in the London 2012 Paralympic Games. The main aim of this study is to focus on the 11-day period of the competition, so that data can be compared with those reported in other competition periods.

\section{METHODS}

Type of study

This study was a component of a large prospective cohort study over the 3-day precompetition period and 11-day competition period of the London 2012 Paralympic Games.

\section{Study participants}

Before the start of the Games, research ethics approval for the study was obtained from both the University of Brighton (FREGS/ES/12/11) and the University of Cape Town Health Sciences Research Ethics Committee (HREC/REF 436/2012). Consent to utilise their medical data for research purposes was obtained from all athletes prior to the Games. The study was coordinated through the International Paralympic Committee (IPC) Medical Committee.

General information about the study was sent by email to all the Chief Medical Officers (CMO) of the teams participating in the Games $(\mathrm{N}=164)$. Further detailed information regarding the components of this study was provided to the team physicians of all delegations that were accompanied by medical staff at the time of a preGames medical briefing. Four countries chose not to participate in the study. The participation and compliance from teams with medical staff was incentivised by entry into a lottery for 20 donated electronic tablet computers allocated by a random draw on completion of the Games.

During the total 14 days of monitoring, a total of 160 National Paralympic Committees (NPCs) and 3565 athletes were studied. As 4 NPCs accounting for 611 athletes chose not to participate in this study, our study sample was representative of $85 \%$ of athletes at the London 2012 Paralympic Games. A total of 49910 athlete-days were monitored in this study, to include 10695 athlete-days in the precompetition period and 39215 athlete-days in the competition period (table 1). There were 2347 male athletes $(65.8 \%$ of all athletes) and 1218 female athletes $(34.2 \%)$ in the study. The mean (+SD) age of the athletes in this study was $30.9 \pm 9.2$ years (minimum $=13$ years, maximum $=67$ years).

\section{Data sources and collection}

Data sources

Three data sources were utilised. The first source was a comprehensive athlete database obtained from the IPC. This contained
Table 1 Athlete-days in countries with and without own medical support in the precompetition, competition and total study period of the London 2012 Paralympic Games

Countries without
own medical

Countries with own support (EMDCS) medical support (EMDCS and WEB-IISS) Total

\begin{tabular}{lrrr} 
NPCs (n) & 82 & 78 & 160 \\
$\begin{array}{l}\text { Athletes (n) } \\
\begin{array}{l}\text { Athlete-days } \\
\text { (precompetition }\end{array}\end{array}$ & 236 & 3329 & 3565 \\
$\begin{array}{l}\text { period) } \\
\begin{array}{l}\text { Athlete-days } \\
\text { (competition period) }\end{array}\end{array}$ & 2596 & 9987 & 10695 \\
$\begin{array}{l}\text { Athlete-days (total } \\
\text { period) }\end{array}$ & 3304 & 36619 & 39215 \\
\hline
\end{tabular}

the following data fields in a deidentified format; accreditation number, country code, sports code (20 sports), gender and age. The second data source was from an electronic medical data capture system (EMDCS; ATOS, France) utilised in previous Olympic and Paralympic Games. London Organising Committee of the Olympic Games and Paralympic Games (LOCOG) sports physicians and medical staff were requested to enter all medical encounters (illness and injury) at both the Paralympic Village polyclinic and at the sports venues via this system.

The third data source was from the medical encounters of staff that provided care to their own teams. To date, these data have been collected by completing a form (paper or electronic format). However, for the London 2012 Paralympic Games a novel system (WEB-IISS) was developed. The methodology used for the construction of the WEB-IISS combined an adaptation of the 2009 Confederation Cup illness reporting system ${ }^{21}$; the 2010 Super Rugby illness reporting system, ${ }^{16}$ the 2010 FIFA World Cup injury and illness reporting system ${ }^{14}$ and the IOC injury and illness surveillance system. ${ }^{4} 5$ The WEB-IISS also incorporated several unique features allowing more clinical detail on injury and illness, as well as exposure data to be captured. The system was further adapted to be applicable to athletes with a disability, and translations were made available.

Data input via the WEB-IISS was facilitated through desktop computer interface, tablet or smart phone. The web-based system involved custom written software to enhance front-end user experience as well as a research-based kernel (QuestBack, Norway), which allowed data extracting and reporting in a spreadsheet format. Unique technical features of this system included (1) login and password provision for designated team medical staff to ensure accurate reporting and security; (2) a colour-coded calendar depicting the days of the Games with different colours indicating if data had been submitted for any particular day and (3) facility for the input of daily number of athletes under care of the medical team on any given day to allow for collection of exposure data. Additionally, the system triggered automated email reminders to CMOs if data had not been recorded for any particular day. Back-end access by the designated system administrator allowed for computation of daily athlete exposure details as well as levels of compliance, and notified the administrator of the countries that had not submitted data for a certain period. This facilitated an in-person visit by the research team to encourage the data entry process.

The system of data entry and storage complied with existing European Union standards for medical data storage. Secure Socket Layer encryption with user authentication as well as 
ICSA-certified firewalls was used to protect the system. Daily server back-ups were performed on mirror (redundant) servers hosted in different countries to further protect data.

Clinical information captured via the WEB-IISS was the same as that which a team physician would obtain normally during clinical assessment of an athlete. Injury information included: disability class, chronicity of the injury, mechanism of acute injury, contributing factors to the injury, stage of the games in which the injury occurred, when during the competition or training session the injury occurred, which protective gear was worn by the athlete, date of onset symptoms, decision to return to play, severity of injury, special investigations used in the assessment of the injury, primary and secondary anatomical areas injured and final diagnosis.

For illness, the information included the following: presenting symptom(s) or sign(s), duration of symptoms (days), the specific final clinical diagnosis (a list of common diagnoses was provided for each body system), the predicted number of days lost from practices or matches and the suspected aetiology of illness (a list of common categories of causes was provided).

Information recorded in the EMDCS with respect to injury was limited to: accreditation number, sport, gender, age, date of injury, main anatomical area of injury and clinical notes (free text). Chronicity was established by retrospective review of three independent clinicians via clinical notes recorded in the system. Information recorded on the EMDCS with respect to illness was limited to: accreditation number, sport, gender, age, date of illness, main system affected and clinical notes (free text).

\section{Data collection}

Data collection was carried out on a daily basis during the study period. This began 3 days before the start of the Games (precompetition period) and ended on the last day of the 11-day Games (competition period). The overall IP and IR for injuries and illnesses are reported for the precompetition period and competition period. However, for the purposes of this manuscript, only the data collected during the competition period were analysed in detail. This period was chosen in order to compare the data with similar existing studies. Results are also presented for the complete period of study (tables 1 and 2).

Teams without their own medical support: Injury and illness data from teams without their own medical support $(n=82$ countries; 236 athletes) were collected through LOCOG via EMDCS. Therefore, detailed medical illness data from countries with no accompanying medical staff was assumed to be reported by the polyclinic and venue medical staff.

Teams with their own medical support: Injury and illness data from teams with their own medical support $(n=78$ countries;
3329 athletes) was collected through both the EMDCS and the WEB-IISS. Although medical staff was requested to report all injuries and illness in their teams via the WEB-IISS, there were instances where athletes reported to the LOCOG services directly, underwent further investigation using the LOCOG systems or had second opinions from LOCOG medical staff. These encounters were thus reported on both systems or only on the EMDCS. A credible algorithm was developed to identify and delete duplicate records in the data. Records having the same dates and same clinical characteristics were considered duplicates.

\section{Definition of illness and injury}

A general definition accepted for reporting injury and illness was defined as any athlete who received medical attention regardless of the consequences with respect to absence from competition or training.

An injury was defined as 'any newly acquired injury as well as exacerbations of preexisting injury that occurred during training and/or competition of the 14 day precompetition and competition period of the London 2012 Paralympic Games'. Acute, acute-on-chronic and chronic injuries were logged. An acute traumatic injury was defined as 'an injury that was caused by an acute precipitating traumatic event'. An acute-on-chronic injury was defined as 'an acute injury in an athlete with symptoms of a chronic injury in the same anatomical area'. A chronic (overuse) injury was defined as 'an injury that developed over days, weeks or months and was not associated with any acute precipitating event'.

A medical illness was defined as 'any newly acquired illness as well as exacerbations of preexisting illness that occurred during training and/or competition or during or immediately before the 2012 Paralympic Games'. Injury and illness data were analysed only after the Games.

\section{Calculation of athlete-days}

\section{Teams without their own medical support}

The exposure data in terms of athlete-days for countries without their own medical support was made on the assumption that the total number of athletes, as published in the IPC athlete database, was static for the duration of the games. The total athlete-days were calculated as follows: total team days (competition period) $\times$ daily team size (for each day).

\section{Teams with their own medical support}

The CMO of each team was requested to capture their daily team size (number of athletes who were under the care of the medical team), and register any new injury or illness.

Table 2 Incidence rate of percentage of athletes with injury and illness reported during the precompetition, competition and total period of the London 2012 Paralympic Games

\begin{tabular}{|c|c|c|c|c|c|c|c|c|c|}
\hline & \multicolumn{3}{|c|}{ Precompetition period ( 3 days) } & \multicolumn{3}{|c|}{ Competition period (11 days) } & \multicolumn{3}{|c|}{ Total period (14 days) } \\
\hline & \multicolumn{3}{|c|}{$95 \% \mathrm{Cl}$} & \multicolumn{3}{|c|}{$95 \% \mathrm{Cl}$} & \multicolumn{3}{|c|}{$95 \% \mathrm{Cl}$} \\
\hline \multicolumn{10}{|l|}{ Injury } \\
\hline IR & 14.8 & 12.6 & 17.3 & 12.1 & 11.0 & 13.3 & 12.7 & 11.7 & 13.7 \\
\hline$\%$ of athletes & 4.3 & 3.6 & 4.9 & 10.9 & 9.8 & 11.9 & 15.1 & 13.9 & 16.3 \\
\hline \multicolumn{10}{|l|}{ Illness } \\
\hline $\mathbb{I R}$ & 14.6 & 12.4 & 17.1 & 12.8 & 11.7 & 13.9 & 13.2 & 12.2 & 14.2 \\
\hline$\%$ of athletes & 3.9 & 3.3 & 4.6 & 10.2 & 9.2 & 11.2 & 14.2 & 13.0 & 15.3 \\
\hline
\end{tabular}


An analysis of the data of teams with their own medical support (WEB-IISS) showed that there was a negligible variation $(\sim 0.5 \%)$ between reported number of athletes in each delegation and the total number of athletes, as published in the IPC athlete database. Therefore, total athlete-days for each country was also calculated as described hereinbefore.

\section{Calculation of the incidence of injury and illness}

The injury and illness IRs were calculated as injuries and illnesses per 1000 athlete-days. During the precompetition period (3 days), competition period (11 days) and total period (14 days), illness and injury data were recorded utilising a total exposure of 49910 athlete-days (table 1). The IR per 1000 athlete-days was reported for all injuries, injuries in different anatomical areas and for various chronicity of injury. Similarly, the IR per 1000 athlete-days was reported for all illnesses, as well as for illnesses in different body systems. The IP was calculated as the number of injuries and illnesses per 100 athletes in the subgroup(s) (\%).

\section{Statistical analysis of data}

Data were in the form of counts, that is, the number of illnesses each athlete contracted. An athlete could sustain an illness in either the precompetition or competition period of the games or in both. Athletes could participate in more than one sport and/or more than one event, and some athletes reported more than one illness for the same period or for a different period.

Standard descriptive statistical analyses were conducted. These include numbers, proportions/percentages (including 95\% CIs) and incidences (including exact 95\% CIs) of illnesses in the total sample as well as genders, age groups, sport types and affected systems during the precompetition and competition period.

\section{RESULTS \\ Injury and illness rates during the precompetition and competition periods}

The overall IR, as well as the IR in the precompetition and competition periods of the London 2012 Paralympic Games is shown in table 2 . In the 14-day study period, the IR of injury was 12.7 (95\% CI 11.7 to 13.7 ). In the precompetition period the IR of injury was 14.8 (95\% CI 12.6 to 17.3), however during the competition period this was 12.1 (95\% CI 11.0 to 13.3). In the precompetition period the percentage of athletes with an injury was $4.3 \%$ (95\% CI $3.6 \%$ to $4.9 \%$ ) while during the competition period this was $10.9 \%$ (95\% CI $9.8 \%$ to $11.9 \%$ ) thus a total of $15.1 \%$ (95\% CI $13.9 \%$ to $16.3 \%)$ of athletes sustained injury during the total observation period.

Similarly, in the total study period, the IR of illness was 13.2 (95\% CI 12.2 to 14.2 ). In the precompetition period the IR of illness was 14.6 (95\% CI 12.4 to 17.1) and during the competition period this was 12.8 (95\% CI 11.7 to 13.9 ). In the precompetition period the percentage of athletes with an illness was $3.9 \%$ (95\% CI $3.3 \%$ to $4.6 \%$ ), and during the competition period this was $10.2 \%$ (95\% CI $9.2 \%$ to $11.2 \%)$. Thus a total of $14.2 \%$ (95\% CI \% 13.0 to $15.3 \%)$ of all athletes sought medical attention for an illness during the total observation period. IRs of injury compared with those of illness showed no significant difference. Furthermore IRs of injury and illness showed no significant difference in the precompetition versus the competition periods.

\section{Injury and illness rates during the competition period}

The incidence, frequency and chronicity of injury during the competition period are shown in table 3 . During this period, a total of 475 injuries were reported in 387 athletes. A total of $10.9 \%$ of all athletes sustained injuries during the competition period. Most of the injuries were acute traumatic injuries (52.2\%) along with acute-on-chronic injuries which accounted for an additional $17.8 \%$ of all injuries. Thus, acute injury (the two latter groups) constituted $70 \%$ of all injuries. The remaining 30\% of injuries were chronic overuse injuries.

The anatomical part most injured during the competition period was the upper limb. Shoulder injuries were most common (83 injuries; 2.1/1000 athlete-days (95\% CI 1.7 to 2.6)), followed by injuries of the wrist and hand (59 injuries; $1.5 / 1000$ athlete-days (95\% CI 1.1 to 1.9$)$ ) and the elbow (40 injuries; $1.0 / 1000$ athletes (95\% CI 0.7 to 1.4 )) (table 4). Further detailed analysis of factors related to injury during the precompetition and competition periods will be reported elsewhere in this edition of the journal. ${ }^{23}$

During the competition period, a total number of 501 cases of illnesses were reported in 365 athletes $(10.2 \%$ of athletes (95\% CI 9.2\% to $11.2 \%)$ ). The overall IR was 12.8 (95\% CI 11.7 to 13.9$)$. The IR of illness in each system is depicted in table 5 . The most common system affected by illness was the respiratory system (IP 27.5\%; IR 3.6 (95\% CI 3.0 to 4.2 )), followed by skin and subcutaneous tissue (IP 18.3\%; IR 2.3 (95\% CI 1.9 to 2.9)) and the digestive system (IP 14.8\%; IR 1.9 (95\% CI 1.5 to 2.4$)$ ). Further detailed analysis of factors relating to illness for the precompetition and competition periods will be reported elsewhere in this edition of the journal. ${ }^{24}$

\section{DISCUSSION}

The main aim of this study was to document the incidence of injury and illness in athletes during the 11-day-competition period of London 2012 Paralympic Games. The first important finding of this study is that, during this period, there is a similar IR of injury and illness (12.1 injuries vs 12.8 illness/1000

Table 3 Incidence rate and percentage of athletes with all injuries reported, acute traumatic injuries, chronic (overuse) injuries and acute-on-chronic injuries during the competition period

\begin{tabular}{lccccc}
\hline & Number of injuries & IR & $\mathbf{9 5 \% ~ C l}$ & \multicolumn{2}{c}{$\begin{array}{l}\text { Number of athletes } \\
\text { with injury }\end{array}$} \\
\hline All injury & 475 & 12.1 & 11.0 to 13.3 & 415 & 11.6 \\
Acute traumatic injury & 248 & 6.3 & 5.6 to 7.2 & 203 & 5.7 \\
Acute-on-chronic injury & 85 & 2.2 & 1.7 to 2.7 & 76 & 2.1 \\
Acute and acute-on-chronic injuries combined & 333 & 8.5 & 7.6 to 9.5 & 279 & 7.8 \\
Chronic (overuse) injury & 142 & 3.6 & 3.0 to 4.3 & 127 & 3.6 \\
\hline IR, incidence rate (injuries per 1000 athlete-days) with $95 \% \mathrm{Cl}$ & & &
\end{tabular}


Table 4 Incidence rate and incidence proportion of injury for each anatomical area during the competition period

\begin{tabular}{|c|c|c|c|c|c|}
\hline & Number of injuries & IR & $95 \% \mathrm{C}$ & & IP \\
\hline Head and face & 12 & 0.3 & 0.2 & 0.5 & 0.3 \\
\hline Neck & 23 & 0.6 & 0.4 & 0.9 & 0.6 \\
\hline Shoulder & 83 & 2.1 & 1.7 & 2.6 & 2.1 \\
\hline Upper arm & 8 & 0.2 & 0.1 & 0.4 & 0.2 \\
\hline Elbow & 40 & 1.0 & 0.7 & 1.4 & 1.0 \\
\hline Forearm & 4 & 0.1 & 0.0 & 0.3 & 0.1 \\
\hline Wrist and hand & 59 & 1.5 & 1.1 & 1.9 & 1.5 \\
\hline Chest wall & 9 & 0.2 & 0.1 & 0.4 & 0.2 \\
\hline Trunk and abdomen & 10 & 0.3 & 0.1 & 0.5 & 0.3 \\
\hline Thoracic spine & 9 & 0.2 & 0.1 & 0.4 & 0.2 \\
\hline Lumbar spine & 31 & 0.8 & 0.5 & 1.1 & 0.7 \\
\hline Pelvis/buttock & 9 & 0.2 & 0.1 & 0.4 & 0.2 \\
\hline Hip/groin & 18 & 0.5 & 0.3 & 0.7 & 0.4 \\
\hline Thigh & 30 & 0.8 & 0.5 & 1.1 & 0.7 \\
\hline Knee & 39 & 1.0 & 0.7 & 1.4 & 1.0 \\
\hline Lower leg & 26 & 0.6 & 0.4 & 0.9 & 0.6 \\
\hline Ankle & 27 & 0.7 & 0.5 & 1.0 & 0.7 \\
\hline Foot & 27 & 0.7 & 0.5 & 1.0 & 0.7 \\
\hline Other & 11 & 0.3 & 0.1 & 0.5 & 0.3 \\
\hline All injuries & 475 & 12.1 & 11.0 & 13.3 & 11.6 \\
\hline
\end{tabular}

IP, incidence proportion (\%).

$\mathrm{IR}$, incidence rate (injuries per 1000 athlete-days) with $95 \% \mathrm{Cl}$.

Incidence of illness and system affected during the competition period.

athlete-days). Of all athletes studied during this period, 10.9\% presented with injury and $10.2 \%$ presented with an illness.

While rates of injury have been reported in the multisport setting previously, ${ }^{1} 281020$ this is the first study of Paralympic athletes to express injuries per 1000 athlete-days. This allows

Table 5 Incidence rate and incidence proportion of illness for each primary system during the competition period

\begin{tabular}{|c|c|c|c|c|}
\hline & $\begin{array}{l}\text { Number of } \\
\text { illnesses }\end{array}$ & IR & $95 \% \mathrm{Cl}$ & IP \\
\hline $\begin{array}{l}\text { Haematological and immune } \\
\text { system }\end{array}$ & 3 & 0.08 & 0.02 to 0.22 & 0.1 \\
\hline Circulatory system & 1 & 0.03 & 0.00 to 0.14 & 0.01 \\
\hline Skin and subcutaneous tissue & 91 & 2.32 & 1.87 to 2.85 & 2.5 \\
\hline Ears and mastoid & 32 & 0.82 & 0.56 to 1.15 & 0.9 \\
\hline Digestive system & 74 & 1.89 & 1.48 to 2.37 & 2.0 \\
\hline $\begin{array}{l}\text { Endocrine, nutritional and } \\
\text { metabolic disease }\end{array}$ & 8 & 0.20 & 0.09 to 0.40 & 0.2 \\
\hline Nervous system & 44 & 1.12 & 0.82 to 1.51 & 1.2 \\
\hline Mental and behavioural disorders & 7 & 0.18 & 0.07 to 0.37 & 0.2 \\
\hline Respiratory system & 138 & 3.52 & 2.96 to 4.16 & 3.8 \\
\hline Genitourinary system & 38 & 0.97 & 0.69 to 1.33 & 1.0 \\
\hline Eye and adnexa & 36 & 0.5 & 0.31 to 0.79 & 0.5 \\
\hline $\begin{array}{l}\text { Other infections and parasitic } \\
\text { disease }\end{array}$ & 20 & 0.1 & 0.01 to 0.18 & 0.4 \\
\hline $\begin{array}{l}\text { Other symptoms and signs, and } \\
\text { abnormal clinical and laboratory } \\
\text { findings }\end{array}$ & 2 & 0.9 & 0.64 to 1.27 & 0.1 \\
\hline $\begin{array}{l}\text { Specific medical conditions related } \\
\text { to sports }\end{array}$ & 7 & 0.2 & 0.07 to 0.37 & 0.1 \\
\hline All illnesses & 501 & 12.80 & 11.7 to 13.9 & 10.2 \\
\hline
\end{tabular}

for comparison with other events of different duration and will also allow for meaningful longitudinal study. Furthermore this is the first study to document rates of illness in Paralympic athletes. While the focus of efforts in sport and exercise medicine with respect to prevention has been concentrated on injury, the findings of this study suggest that illness is at least as prevalent as injury during the competition period. Therefore, efforts should be intensified to further study factors related to illness in further protect the health of the athlete.

The second important finding of this study is that in contrast to results of similar epidemiological studies of injury patterns in Olympic and other elite competitive able-bodied environments, upper limb injuries are more common than lower limb injuries within this cohort. ${ }^{3}$ Indeed, analysis of the IP of injuries indicates that upper limb injuries constitute $41 \%$ of all injuries and lower limb injuries constitute $35 \%$ of all injuries. In this population the most frequently injured region is the shoulder $(17 \%$ of all injuries). This finding is not surprising given the fact that athletes utilising wheelchairs (athletics, wheelchair basketball, wheelchair tennis, wheelchair rugby, wheelchair fencing and boccia) constitute a significant proportion of the Games' participants. ${ }^{3}$ Most injuries were acute injuries (52\%) in keeping with findings from similar studies. ${ }^{2} 108$ Future injury prevention research should be focused on understanding the factors related to injury of these specific anatomical regions.

The third main finding was that an illness was reported in $10.9 \%$ of athletes during the competition period. This figure is less than those reported for the 2009 FIFA Confederations Cup, ${ }^{21}$ the 2010 FIFA World Cup $(12 \%)^{14}$ and 2010 Super Rugby Competition (75\%) ${ }^{16}{ }^{17}$ but more than those reported for the 2009 FINA World Championships $(7.1 \%),{ }^{11}$ the 2009 IAAF World Championships $(6.7 \%)^{12}$ and the 2010 Winter Olympic games (6.7\%). ${ }^{10}$ However, this comparison is limited owing to different durations of competition. It is important to compare IR of illness wherever possible. The IRs of illness of 12.8 during the competition period in this study of Paralympic athletes are higher than those recorded in the 2010 FIFA World Cup $(7.7)^{14}$ and the 2009 World Championships in athletics, (7.6) but lower than those reported for the 2010 Super Rugby Competition $(20.7)^{16}$ 17 and the 2009 FIFA Confederations Cup (16.5). ${ }^{21}$

In the present study, the most affected system was the respiratory system $(27.4 \%)$, followed by skin and subcutaneous tissue $(18.3 \%)$ and the gastrointestinal system (14.5\%). Although the percentage is the highest in the respiratory system, nonrespiratory illness is higher in athletes with a disability, in comparison with those patterns reported in a number of other studies of able-bodied athletes including rugby union players, football players, track and field athletes, athletes at the Winter Olympic Games and aquatic sports. ${ }^{10-12} 141617$ The frequency of genitourinary illness in this study was $7.6 \%$ of all illnesses, which is higher than that documented in similar epidemiological studies of able-bodied athletes. ${ }^{12} 252610$ This is likely owing to the presence of athletes with spinal cord injury in the study population. Reasons for differences between rates of illness in different competition settings and illness patterns across the different disabilities require further detailed analyses of the data.

Finally, a particular novel contribution of this study was the development and implementation of the WEB-IISS. Feedback from the clinicians using this system indicated that the system was reliable and easily accessed. Although an identified barrier was the perception of increased workload for a number of clinicians, as experience with using the system progressed, it was reported to the research team that it took the clinician an average of $3 \mathrm{~min}$ per injury and 2 min per illness to log all fields 
of data. As there was Wi-Fi coverage at all Paralympic venues, this system allowed the clinician a freedom to log data wherever and whenever he or she wished. Thus, acceptance of use of this system was gained by most of the team clinicians.

A limitation of this study was that two different electronic systems were used to capture data. The WEB-IISS captured more data fields with respect to both injury and illness, thus allowing a significantly more detailed analysis to be conducted from data entered onto this system. It was notable that the two systems were better aligned in terms of the illness data than the injury data.

Preferably in the future, one system of data capture should be used or the systems harmonised to collect the same data fields and minimise duplicate entries. A further limitation was that four countries chose not to participate in this study, thereby excluding $14.7 \%$ of athletes from the analysis. It was also recognised that despite the advantages of the WEB-IISS, underreporting of illness and injury by the medical teams could occur. However, despite the aforementioned limitations, this study represents the largest study to date of injury and illness in Paralympic athletes.

In summary, injury and illness surveillance has been successfully implemented at the London 2012 Paralympic Games using both an existing as well as a novel web-based system for utilisation by team physicians. IR of illness and injury are comparable during the Games, yet patterns of injuries and illnesses in Paralympic athletes are different to able-bodied athletes. Upper limb injuries and non-respiratory illness (including urinary tract illnesses) in the Paralympic population are more prevalent than in able-bodied athletes. These findings highlight the need for more data to enable different prevention strategies. This study is the largest prospective study of Paralympic athletes and forms a baseline for future longitudinal study.

\section{What are the new findings?}

- Illnesses are at least as prevalent as injuries in Paralympic athletes.

- Most injuries are acute injuries at the Paralympic Games.

- Patterns of injuries and illness in Paralympic athletes are different to able-bodied athletes.

- Upper limb injuries including shoulder, hand and wrist and elbow are more common than lower limb injuries.

- Non-respiratory illnesses (including urinary tract illnesses) are more common than respiratory illnesses in Paralympic athletes.

\section{How might it impact on clinical practice in the near} future?

- Team physicians are now aware of different patterns of injuries and illnesses in Paralympic athletes and can plan different prevention strategies based on this information.

- A novel web-based system for injury and illness surveillance is available for collection of data.

\section{Author affiliations}

'Department of Human Biology, UCT/MRC Research Unit for Exercise Science and Sports Medicine, University of Cape Town, Cape Town, South Africa

${ }^{2}$ International Olympic Committee (IOC) Research Centre, Cape Town, South Africa ${ }^{3}$ Biostatistics Unit, Medical Research Council, Parow, South Africa

${ }^{4}$ Department of Physical Medicine and Rehabilitation, Spaulding Rehabilitation Hospital, Harvard Medical School, Boston, USA
${ }^{5}$ International Paralympic Committee (IPC) Medical Committee, Bonn, Germany ${ }^{6}$ Faculty of Kinesiology, Sport Injury Prevention Research Centre, University of Calgary, Calgary, Canada

${ }^{7}$ International Olympic Committee (IOC) Research Centre, Calgary, Canada ${ }^{8}$ National Center of Medicine and Sports Sciences, National Commission of Physical Culture and Sport in the Mexican Paralympic Centre, MexicoCity, Mexico ${ }^{9}$ Blanquerna Faculty of Sport Sciences, Ramon Llull University, Barcelona, Spain ${ }^{10}$ Sports Medicine Department, Isala Klinieken, Zwolle, the Netherlands

${ }^{11}$ Faculty of Kinesiology and Recreation Management, Health, Leisure and Human Performance Research Institute, University of Manitoba, Winnipeg, Canada

${ }^{12}$ Sussex Centre for Sport and Exercise Medicine, University of Brighton, Eastbourne, UK

${ }^{13}$ Physical Medicine and Rehabilitation, Orthopaedic Center, University of Utah, Salt Lake City, Utah, USA

Acknowledgements We would like to acknowledge the significant contributions of the following individuals, who contributed to the work of the research team during the London 2012 Paralympic Games: Dr Richard Budgett, Dr Stuart Miller, Dr Harry Benjamin-Lang, Mr Greg Vice and Ms Janey Orr. The authors would also like to thank the team of physicians and their medical staff who gave their time to collect the data for this project on a daily basis. We also would like to thank the athletes and the administrators for their support with the project. The authors wish to thank Dr Gabrielle Prinsloo for her assistance with this project, particularly the data management and coordination of the submission of the manuscript. This study was approved and supported by the International Paralympic Committee and supported by Acer.

Funding Financial support for this study was received from the IOC Research Centre in Cape Town.

Competing interests None.

Patient consent Obtained.

Provenance and peer review Not commissioned; internally peer reviewed.

\section{REFERENCES}

1 Webborn N, Willick S, Reeser JC. Injuries among disabled athletes during the 2002 Winter Paralympic Games. Med Sci Sports Exerc 2006;38:811-15.

2 Webborn N, Willick S, Emery CA. The injury experience at the 2010 winter paralympic games. Clin J Sport Med 2012;22:3-9.

3 Webborn N, Van de Vliet P. Paralympic medicine. Lancet 2012;380:65-71.

4 Junge $A$, Engebretsen L, Alonso JM, et al. Injury surveillance in multi-sport events: the International Olympic Committee approach. Br J Sports Med 2008;42:413-21.

5 Junge A, Dvorak J, Graf-Baumann T, et al. Football injuries during FIFA tournaments and the Olympic Games, 1998-2001: development and implementation of an injury-reporting system. Am J Sports Med 2004;32(Suppl 1):80S-9S

6 Alonso JM, Edouard P, Fischetto $G$, et al. Determination of future prevention strategies in elite track and field: analysis of Daegu 2011 IAAF Championships injuries and illnesses surveillance. Br J Sports Med 2012;46:505-14.

7 Ferrara MS, Buckley WE, McCann BC, et al. The injury experience of the competitive athlete with a disability: prevention implications. Med Sci Sports Exerc 1992;24:184-8

8 Junge $A$, Engebretsen L, Mountjoy ML, et al. Sports injuries during the Summer Olympic Games 2008. Am J Sports Med 2009;37:2165-72.

9 Crim JR. Winter sports injuries. The 2002 Winter Olympics experience and a review of the literature. Magn Reson Imaging Clin N Am 2003;11:311-21.

10 Engebretsen L, Steffen K, Alonso JM, et al. Sports injuries and illnesses during the Winter Olympic Games 2010. Br J Sports Med 2010;44:772-80.

11 Mountjoy $M$, Junge $A$, Alonso JM, et al. Sports injuries and illnesses in the 2009 FINA World Championships (Aquatics). Br J Sports Med 2010;44:522-7.

12 Alonso JM, Tscholl PM, Engebretsen $L$, et al. Occurrence of injuries and illnesses during the 2009 IAAF World Athletics Championships. Br J Sports Med 2010;44:1100-5.

13 Alonso JM, Junge $A$, Renstrom $P$, et al. Sports injuries surveillance during the 2007 IAAF World Athletics Championships. Clin J Sport Med 2009;19:26-32.

14 Dvorak J, Junge A, Derman W, et al. Injuries and illnesses of football players during the 2010 FIFA World Cup. Br J Sports Med 2011;45:626-30.

15 Dvorak J, Junge A, Grimm K, et al. Medical report from the 2006 FIFA World Cup Germany. Br J Sports Med 2007;41:578-81; discussion 81

16 Schwellnus MP, Derman WE, Page T, et al. Illness during the 2010 Super 14 Rugby Union tournament-a prospective study involving 22676 player days. $\mathrm{Br}$ J Sports Med 2012;46:499-504.

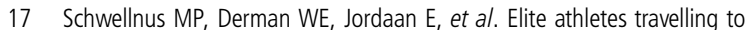
international destinations $>5$ time zone differences from their home country have a 2-3-fold increased risk of illness. Br J Sports Med 2012:46:816-21. 
18 Burham R, Newell E, Steadward R. Sports Medicine for the physically disabled: the Canadian team experience at the 1988 Seoul Paralympic Games. Clin J Sports Med 1991;1:193-6.

19 Nyland J, Snouse SL, Anderson M, et al. Soft tissue injuries to USA Paralympians at the 1996 summer games. Arch Phys Med Rehabil 2000;81:368-73.

20 Reynolds J, Stirk A, Thomas A, et al. Paralympics-Barcelona 1992. Br J Sports Med 1994:28:14-17.

21 Theron N, Schwellnus MP, Derman WE, et al. "Illness and injuries in elite football players-a prospective cohort study during the FIFA Confederations Cup 2009". Clin I Sport Med In Press.

22 Ruedl G, Schobersberger W, Pocecco E, et al. Sport injuries and illnesses during the first Winter Youth Olympic Games 2012 in Innsbruck, Austria. Br I Sports Med 2012;46:1030-7.
23 Willick S, Webborn N, Emery C, et al. The epidemiology of injuries at the London 2012 Paralympic Games Br J Sports Med (in press).

24 Schwellnus MP,, Derman WE, Jordaan E, et al. Factors associated with illness in athletes participating in the London 2012 Paralympic Games—a prospective cohort study involving 49910 athlete-days. Br I Sports Med (in press).

25 Derman EW. Medical care of the South African Olympic team - the Sydney 2000 experience. S Afr I Sports Med 2003;15:22-5.

26 Derman W. Profile of medical and injury consultations of Team South Africa during the XXVIIIth Olympiad, Athens 2004. S Afr I Sports Med 2007; 19:80-3. 